\title{
Cholinesterase and Glycation Inhibition Assay of Several Metabolites Obtained from Plant and Fungi
}

\author{
Rashedul Islam ${ }^{1 *}$, Mohiminul Adib ${ }^{1 *}$, Monira Ahsan ${ }^{1}$, Md. Mustafizur Rahman ${ }^{2}$ \\ and Md. Abdul Mazid ${ }^{1}$ \\ ${ }^{1}$ Department of Pharmaceutical Chemistry, Faculty of Pharmacy, University of Dhaka \\ Dhaka-1000, Bangladesh \\ ${ }^{2}$ Pharmacy Discipline, Khulna University, Khulna, Bangladesh
}

(Received: September 03, 2018; Accepted: January 20, 2019; Published (Web): April 01, 2019)

\begin{abstract}
ABSTRUCT: Cholinesterase inhibition is one of the major strategies to develop better quality anti-Alzheimer's drug, while inhibition of glycation pathway is a useful therapeutic strategy to treat diabetic complications. This study was designed to evaluate the anti-acetylcholinesterase, anti-butyrylcholinesterase and anti-glycation activities of 8 secondary metabolites namely, RS-8, RS-22C (arborinine), CL-1 (betulinic acid), CL-2 (ursolic acid), CCL-1 (cajaninstilbene acid), CP-1 (beta-sitosterol), HS-1 (anhydrofusarubin) and HS-2 (methylether of fusarubin). It was found that RS-8 and arborinine showed promising activity in inhibiting acetylcholinesterase with $\mathrm{IC}_{50}$ values of 24.40 \pm 0.39 and $13.14 \pm 0.07$, respectively. Anhydrofusarubin and methyl ether of fusarubin exhibited moderate activities with $\mathrm{IC}_{50}$ values of $47.82 \pm 0.54$ and $44.58 \pm 0.8$. Arborinine and cajaninstilbene acid potentially inhibited butyrylcholinesterase with $\mathrm{IC}_{50}$ values of $26.34 \pm 0.31$ and $25.82 \pm 0.34$, respectively, but other metabolites did not show such inhibitory activities. Inhibition of glycation process was evaluated by bovine serum albumin assay but none of the metabolites significantly inhibited the glycation pathway.
\end{abstract}

Key words: Secondary metabolites, cholinesterase, acetylcholinesterase, butyrylcholinesterase, glycation

\section{INTRODUCTION}

Alzheimer's disease (AD) and diabetes mellitus (DM) are the two major health concerns globally. Alzheimer's disease is an irreversible, progressive brain disorder that slowly destroys memory and thinking skills and eventually the ability to carry out the simplest tasks. It occurs due to the cholinesterase induced declination of neurotransmitters. Cholinesterases are enzymes involved in breaking down neurotransmitters like acetylcholine (ACh) and butyrylcholine $(\mathrm{BuCh})$ and are respectively called acetylcholinesterase (AChE) and butyrylcholinesterase (BuChE). ${ }^{1}$

Correspondence to: Md Abdul Mazid

E-mail: ma.mazid@du.ac.bd

*Authors contributed equally

Dhaka Univ. J. Pharm. Sci. 18(1): 00-00, 2019 (June) DOI: https://doi.org/10.3329/dujps.v18i1.41424
Studies have shown that AD is defined by the rapid loss of AChE activity in the early stages of the disease, along with an increasing ratio of AChE as the disease progresses. ${ }^{2,3}$ Furthermore, BuChE has been found to be capable of compensating for the missing AChE catalytic functions in the synaptic cleft, and its activity increases by 30\%-60\% during $\mathrm{AD}^{4-7}$ Due to the role of BuChE in the hydrolysis of Ach, the inhibition of both ChEs using a dual inhibitor should result in increased levels of ACh in the brain, which provide more successful clinical efficacy of $\mathrm{AD}^{8}$

Diabetes mellitus (DM), commonly referred to as diabetes, is a group of metabolic diseases in which there are high blood sugar levels over a prolonged period. High blood sugar level occurs due to the increased glycation of proteins in the blood plasma. Glycation of proteins [advanced glycation end 
products (AGEs)] occurs through non-enzymatic condensation reaction between reducing sugars and amino groups of proteins that undergo rearrangements to stable ketoamines. These AGEs are thought to be the major causes of a number of diabetic complications. ${ }^{9}$

Although, synthetic drugs such donepezil, neostigmine and rivastigmine are available for the symptomatic treatment of $\mathrm{AD}$, search for newer molecules from natural products has gained much attention by the researchers worldwide because of lower cost and less side effects. Majority of the secondary metabolites with potential AChE and BuChE inhibitory activity are alkaloids followed by terpenes, sterols, flavanoids, and glycosides. Examples of some secondary metabolites that have shown anticholinesterase activity include vasicinone, vasicine, harmine, deoxyvasicinone, deoxyvasicine, harmaline, harmol, and harmane. ${ }^{10}$ Most of the compounds are isolated from Buxaceae, Amaryllidaceae, Lycopodiaceae, Lamiaceae, Chenopodiaceae, Papaveraceae, Apocynaceae, and Labiatae species. ${ }^{11,12}$ Many indigenous plants have been used in folkloric medicine to manage diabetes from which some of them have received scientific attention. ${ }^{13}$ Several substances like glycosides, alkaloids, terpenoids, flavonoids, carotenoids etc. are reported to have antidiabetic effects such as diosmin, tangeritin, lycopene, syringin etc. ${ }^{14}$

In this present study eight (8) isolated secondary metabolites namely, RS-8, RS-22C (arborinine) isolated from Ravenia spectabilis, CL-1 (betulinic acid) and CL-2 (ursolic acid) obtained from Chamaedorea linearis, CCL-1 (cajaninstilbene acid) obtained from Cajanus cajan, CP-1 (beta-sitosterol) obtained from Carica papaya, HS-1 (anhydrofusarubin) and HS-2 (methylether of fusarubin) obtained from endophytic fungal strain, Cladosporium species, were assessed for the inhibition of AChE, BuChE and glycation pathway.

\section{MATERIALS AND METHODS}

Isolated secondary metabolites. Secondary metabolites that were used to assess the preliminary inhibitory effect on AChE, BuChE and glycation pathway are listed in figure 1. A brief of the sources of the isolated metabolites are: RS- 8 and RS-22 were isolated from the plant $R$. spectabilis (Family: Rutaceae) through vacuum liquid chromatographic (VLC) separation technique. Later on RS-22C was confirmed as arborinine (1-hydroxy-2, 3-dimethoxy10-methyl-9(10H)-acridinone) by nuclear magnetic resonance; while structure of RS- 8 is yet to be confirmed. ${ }^{15}$ CL-1 (betulinic acid) and CL-2 (ursolic acid) were obtained from the plant $C$. linearis (Family: Myrtaceae) $;{ }^{16}$ CCL-1 (cajaninstilbene acid) was obtained from C. cajan (Family: Fabaceae); ${ }^{17}$ CP-1 (beta-sitosterol) was obtained from C. papaya (Caricaceae). ${ }^{18}$ On the other hand, HS-1 (anhydro fusarubin) and HS-2 (methylether of fusarubin) were obtained from the endophytic fungal strain, Cladosporium species isolated from $R$. serpentina (Family Rutaceae). ${ }^{19}$

Materials and chemicals. 5, 5'-dithio-bis-(2nitro) benzoic acid (DTNB), acetylcholine iodide, butyrylcholine iodide, Triton X-100, BCA (bicinchoninic acid) kit, trichloroacetic acid and rutin were purchased from (Sigma-Aldrich, Germany), Tris- $\mathrm{HCl}$ and bovine serum albumin were from Merck, Germany). Donepezil was a kind gift from Incepta Pharmaceuticals Ltd., Bangladesh. Other chemicals required were collected from local sources.

Acetylcholinesterase inhibition assay. The inhibition of $\mathrm{AChE}$ was assessed following Ellman method $^{20,21}$ with minor modification using acetylthiocholine iodide as a substrate. As a source of $\mathrm{AChE}$, rat brains were homogenized in a homogenizer with 5 times of a homogenation buffer [10 mM Tris- $\mathrm{HCl}$ (pH 7.2), which contained $1 \mathrm{M}$ $\mathrm{NaCl}, 50 \mathrm{mM} \mathrm{MgCl}_{2}$ and $1 \%$ Triton X-100], ${ }^{22}$ and then centrifuged at $10,000 \mathrm{rpm}$ for $15 \mathrm{~min}$. The supernatant so obtained was used as an enzyme source. The process of enzyme preparation was carried out at $4{ }^{\circ} \mathrm{C}$ and the protein concentration was measured using the BCA (bicinchoninic acid kit) 
using BSA as a protein standard. To carry out the reaction, each tested compound or standard $(500 \mu \mathrm{l})$ was mixed with an enzyme solution $(500 \mu \mathrm{l})$ and incubated at $37^{\circ} \mathrm{C}$ for 15 minutes, and then Ellman's reaction mixture [(3.5- $\mathrm{ml} 0.5 \mathrm{mM}$ acetylthiocholine, $1 \mathrm{mM} \mathrm{5,5}$-dithio-bis-(2-nitro) benzoic acid) in a 50 $\mathrm{mM}$ sodium phosphate buffer ( $\mathrm{pH}$ 8.0)] was added. Immediately after adding Ellman's reaction mixture, the rate of hydrolysis by acetylcholinesterase was monitored spectrophotometrically taking absorbance at $405 \mathrm{~nm}$. Recording of absorbance was repeated for $10 \mathrm{~min}$ at $2 \mathrm{~min}$ intervals to confirm the linearity of the reaction. Saline water in place of enzyme solution was used to carry out a blank reaction and donepezil was used as reference drug in the inhibitory assay. The inhibition of AChE activity was calculated in percentage using the following formula:

$$
\% \text { of inhibition of AChE activity }=\frac{\text { (Absorbance of control }- \text { Absorbance of test sample })}{} \times 100
$$

\section{Absorbance of control}

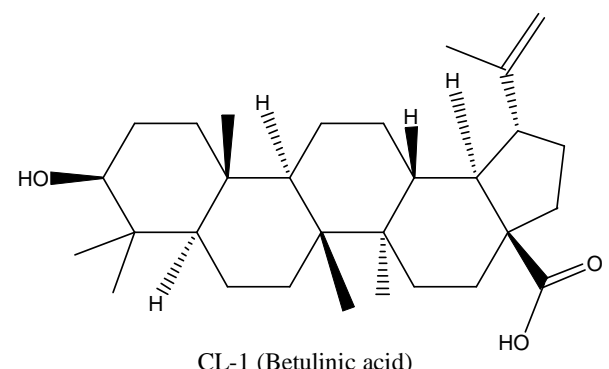

CL-1 (Betulinic acid) Source: Chamaedorea linearis

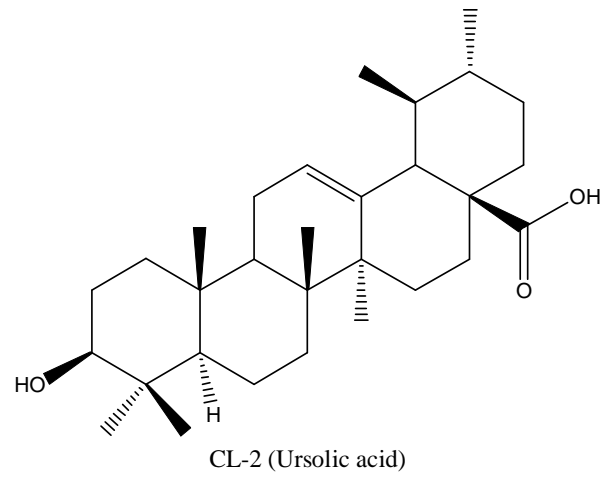

Source: Chamaedorea linearis<smiles>COc1cc2c(c(O)c1O)c(=O)c1ccccc1n2C</smiles><smiles>COc1cc(O)c2c(c1O)C(=O)C1=C(COC(C)(OC)C1)C2=O</smiles><smiles>CC[C@H](CC[C@H](C)[C@]1(C)CC[C@H]2[C@H]3CC=C4C[C@@H](C)CC[C@]4(C)[C@H]3CC[C@]21C)C(C)C</smiles>

RS-22C (Arborinine)

HS-2 (Methylether of fusarubin) Source: Cladosporium sp.

CP-1 (Beta-sitosterol) Source: Ravenia spectabilis<smiles>COc1cc(/C=C/c2ccccc2)c(C(=O)O)cc1CC=C(C)C</smiles>

CCL-1 (Cajaninstilbene acid) Source: Cajanus cajan<smiles>COC1=CC(=O)c2c(O)c3c(c(O)c2C1=O)CC(C)(O)OC3</smiles>

HS-1 (Anhydrofusarubin) Source: Cladosporium sp.

Figure 1. Secondary metabolites used for screening cholinesterase and glycation inhibition assay. 
Butyrylcholinesterase inhibition assay. BuChE assay was performed according to the same method as described for $\mathrm{AChE}$ inhibition assay using butyrylthiocholine iodide as a substrate. However, as a source of enzyme, the human blood was homogenized in a homogenizer with 5 volumes of a homogenation buffer $[10 \mathrm{mM}$ Tris- $\mathrm{HCl}(\mathrm{pH} 7.2)$, which contained $1 \mathrm{M} \mathrm{NaCl}, 50 \mathrm{mM} \mathrm{MgCl}_{2}$ and $1 \%$ Triton X-100, and centrifuged at $10000 \mathrm{rpm}$ for 15 min, and the resulting supernatant was used as an enzyme. The inhibition of BuChE activity was calculated in percentage using the same formula as mentioned above for AChE inhibition assay.

Glycation inhibition assay. Inhibition of glycation pathway was assessed using the bovine serum albumin (BSA) assay through Maillard reaction. $^{23}$ In all experiments, the final reaction volume was $1.0 \mathrm{ml}$ and carried out in $1.5 \mathrm{ml}$ Eppendorf tubes. In brief, $500 \mu \mathrm{l}$ of BSA $(1 \mathrm{mg} / \mathrm{ml}$ concentration) was incubated with glucose $400 \mu \mathrm{l}$ (500 mM final concentration) and $100 \mu \mathrm{l}$ sample; while $100 \mu \mathrm{l}$ phosphate buffer saline was used as the sample control and $100 \mu \mathrm{l}$ rutin as the reference standard. A negative control was carried out at the same time with BSA $500 \mu \mathrm{l}(1 \mathrm{mg} / \mathrm{ml}$ concentration $)$, $400 \mu \mathrm{l}$ phosphate buffer saline and $100 \mu 1$ sample incubated under same conditions. The reaction was allowed to proceed at $60^{\circ} \mathrm{C}$ for 24 hours and terminated by adding $10 \mu \mathrm{l}$ of $100 \%$ (w/v) TCA. The TCA added mixture was kept at $4^{\circ} \mathrm{C}$ for 10 minutes and centrifuged 4 minutes at $13000 \mathrm{rpm}$. The precipitate was re-dissolved with alkaline phosphate buffer saline ( $\mathrm{pH} 10)$ and was quantified for the relative amount of glycated BSA based on fluorescence intensity by Hitachi Fluorescence Spectrophotometer (f-7000). The excitation and emission wavelength used were at $370 \mathrm{~nm}$ and 440 $\mathrm{nm}$, respectively. Each sample was analyzed in eight concentrations in triplicate manner. Inhibition of glycation was calculated in percentage (\%) using the formula given below and the sample concentration required for the $50 \%$ of inhibition was calculated.

$\%$ Inhibition $=\{(\mathrm{Fc}-\mathrm{Fb})-(\mathrm{Fs}-\mathrm{Fsb}) /(\mathrm{Fc}-\mathrm{Fb})\} \times 100$
Where, $\mathrm{Fc}=$ florescence of incubated BSA, glucose and DMSO (control), $\mathrm{Fb}=$ florescence of incubated BSA alone (blank), Fs = florescence of incubated BSA, glucose and tested compound or rutin and $\mathrm{Fsb}=$ florescence of incubated BSA with the tested compound or rutin

Statistical analysis. The results are presented as mean \pm SEM (standard errors) of triplicate experiment. The $\mathrm{IC}_{50}$ values of the compounds were evaluated by non-linear regression analysis using GraphPad Prism Data Editor for Windows, Version 6.0 (GraphPad Software Inc., San Diego, CA). The data were analyzed by one-way ANOVA $p<0.05$ and $\mathrm{p}<0.01$ were considered as statistically significant.

\section{RESULTS AND DISCUSSION}

In vitro $\mathrm{AChE}$ inhibitory activity. Cholinesterase hydrolyses the choline esters such as acetylcholine, butyrylcholine, etc. These choline esters play an important role in the transmission of nerve impulse. Hence, inhibition of cholinesterases has become an important target for the treatment of neurodegenerative disorders, including Alzheimer's disease. $^{24}$ In this study, 8 isolated secondary metabolites were assessed for $\mathrm{AChE}$ and $\mathrm{BuChE}$ inhibitory activities and their results are shown in table 1. From the obtained data, it is observed that, RS-8 and RS-22C (arborinine) showed significant inhibition of AChE compared to the standard donepezil. Arborinine at a concentration of $25 \mu \mathrm{g} / \mathrm{ml}$ inhibited 56.34\% AChE activities, while the standard drug donepezil inhibited $68.41 \%$ activities of cholinesterase at the same concentration. Activity was found to be increased at higher dose. RS-8, HS-1 and HS-2 also significantly inhibited AChE activities with values of $49.78,44.40$ and $42.45 \%$, respectively. The inhibitory effects were found to be increased with increased dose and these activities were showed in table 1. The inhibition of cholinesterase was found promising with RS-22C (arborinine) which was compared to other tested compounds. This finding suggests that RS-22C might be a lead compound to 
develop future drug in the treatment of AD. Previous study reported the effect of arborinine against $\mathrm{AChE}^{26}$, malaria ${ }^{27}$ and cancer cells. ${ }^{28,29}$ The present study further confirm the effect of arborinine in inhibiting AChE.

In vitro BuChE inhibitory activity. In assessment of the butyrylcholinesterase inhibitory activities, as shown in table 1 , the $\mathrm{IC}_{50}(\mu \mathrm{g} / \mathrm{ml} \pm$ SEM) values were found to be $49.88 \pm 0.822$ for RS$8,26.34 \pm 0.314$ for RS-22C (arborinine) and 25.82 \pm 0.3403 for CCL-1 (cajaninstilbene acid). Comparing the activity with standard donepezil, RS-22C (arborinine) and CCL-1 (cajaninstilbene acid) showed promising activities, whereas RS-8 (arborinine) exhibited moderate activity. Previous study reported the effect of cajaninstilbene acid activities against D-amino acid oxidase (DAAO), $\mathrm{AChE}$ and $\mathrm{BuChE},{ }^{30}$ whereas arborinine exhibited BuChE inhibitory activities. ${ }^{31}$ The present study further confirm the effect of arborinine and cajaninstilbene acid in inhibiting BuChE. A comparison of the $\mathrm{AChE}$ and $\mathrm{BuChE}$ inhibition by the tested secondary metabolites are presented in figure 2. From the figure, it was found that arborinine, fusarubin and anhydrofusarubin more potentially inhibited $\mathrm{AChE}$ than $\mathrm{BuChE}$; while cajaninstilbene acid more potentially inhibited $\mathrm{BuChE}$ than that of AChE.

Table 1. Anticholinesterase activity of secondary metabolites obtained from plants and endophytic fungi where donepezil was used as standard drug.

\begin{tabular}{lcc}
\hline Tested compounds & $\begin{array}{c}\text { AChE inhibition } \\
\left(\mathrm{IC}_{50}(\mu \mathrm{g} / \mathrm{ml}) \pm \mathrm{SEM}\right)\end{array}$ & $\begin{array}{c}\text { BuChE inhibition } \\
\left(\mathrm{IC}_{50}(\mu \mathrm{g} / \mathrm{ml}) \pm \mathrm{SEM}\right)\end{array}$ \\
\hline Donepezil & $6.31 \pm 0.09$ & $11.93 \pm 0.13$ \\
(RS-8) & $24.40 \pm 0.39$ & $49.88 \pm 0.82$ \\
Arborinine (RS-22C) & $13.14 \pm 0.07$ & $26.34 \pm 0.31$ \\
Betulinic acid (CL-1) & $160 \pm 2.31$ & $108.58 \pm 1.20$ \\
Ursolic acid (CL-2) & $252.14 \pm 5.27$ & $309.80 \pm 3.01$ \\
Cajaninstilbene acid (CCL-1) & $117.12 \pm 2.46$ & $25.82 \pm 0.34$ \\
Bita-sitosterol (CP-1) & $208.16 \pm 2.11$ & $288.52 \pm 3.17$ \\
Anhydrofusarubin (HS-1) & $47.82 \pm 0.54$ & $398.72 \pm 18.57$ \\
Methylether of Fusarubin (HS-2) & $44.58 \pm 0.80$ & $196.46 \pm 4.30$ \\
\hline
\end{tabular}

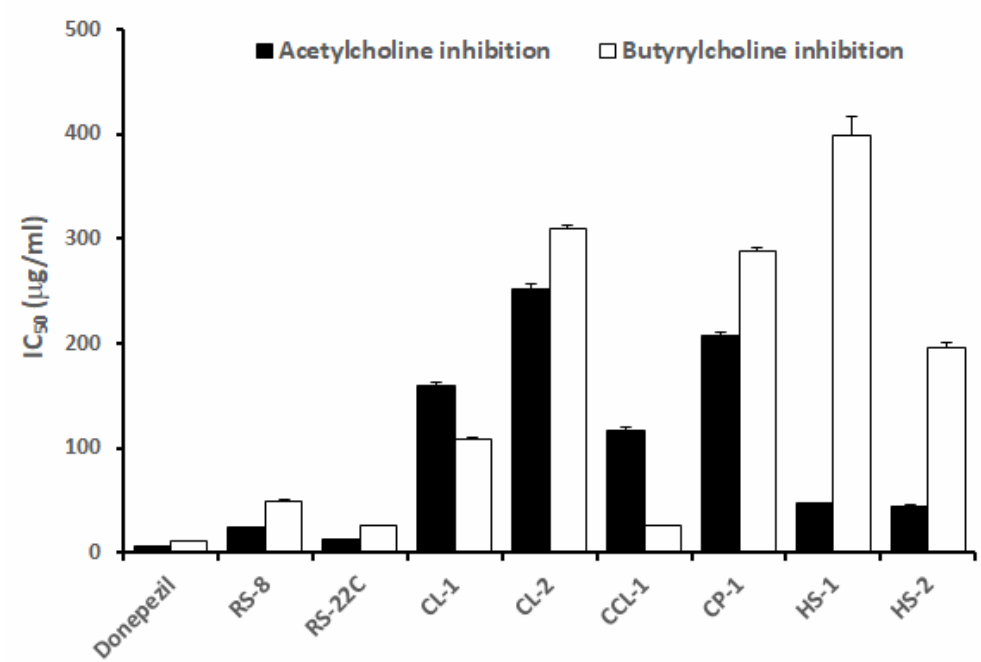

Figure 2. Comparison of acetylcholinesterase and butyryulcholinesterase inhibitory activities by secondary metabolites and donepezil as standard drug. 
In vitro glycation pathway inhibition activity. These secondary metabolites were screened for antiglycation activities using the bovine serum albumin (BSA) assay. The antiglycation activities were presented as $\mathrm{IC}_{50}$ (Inhibitory concentration $50 \%)(\mu \mathrm{g} / \mathrm{ml} \pm \mathrm{SEM})$ and the values were showed in table 2. Glycation process in human body is a key molecular pathway for diabetic complications like diabetes retinopathy, diabetic nephropathy etc. Rutin as standard drug potentially inhibit glycation process in our body. However, comparing the study data of the isolated secondary metabolites with that of rutin, it was found that none of the tested compounds showed any antiglycation activities.

Table 2. Antiglycation activity of secondary metabolites obtained from plants and endophytic fungi where rutin was used as standard.

\begin{tabular}{lc}
\hline Tested compounds & $\left(\mathrm{IC}_{50}(\mu \mathrm{g} / \mathrm{ml}) \pm \mathrm{SEM}\right)$ \\
\hline Rutin & $46.77 \pm 0.42$ \\
RS-8 & $282.25 \pm 2.14$ \\
Arborinine (RS-22C) & $234.36 \pm 1.91$ \\
Betulinic acid (CL-1) & $320.31 \pm 5.22$ \\
Ursolic acid (CL-2) & $308.26 \pm 1.24$ \\
Cajaninstilbene acid (CCL-1) & $187.83 \pm 2.74$ \\
Bita-sitosterol (CP-1) & $470.37 \pm 12.90$ \\
Anhydrofusarubin (HS-1) & $220.60 \pm 1.26$ \\
Methylether of Fusarubin (HS-2) & $212.54 \pm 0.16$ \\
\hline
\end{tabular}

\section{CONCLUSION}

Only three cholinesterase inhibitors such as donepezil, galantamine, rivastigmine and an NMDA receptor antagonist, memantine, currently approved drugs by Food and Drug Administration (FDA) are used to treat $\mathrm{AD}$. The purpose of cholinesterase inhibitors is to inhibit the degradation of acetylcholine within synapses, resulting in increased amount of acetylcholine. Memantine, which is a partial NMDA receptor antagonist, protects neurons from glutamate-induced excitatory damages. ${ }^{32}$ The cholinesterase inhibitors employed in current treatments are limited and they show a wide variety of toxic effect including insomnia, anorexia, diarrhea, fatigue, nausea, gastrointestinal disorders and cardiovascular disorders. ${ }^{33,34}$ Therefore, researchers have focused their attention towards the discovery of new drugs from natural sources such as plants, which have enormous potential for the treatment of $\mathrm{AD}$. Here RS-22C (arborinine) showed significant anticholinesterase activity which has not been seen before, and in case of butyrylcholinesterase inhibitory activities, CCL-1 (cajaninstilbene acid) showed the moderate activity. Our preliminary result suggest that arborinine and cajaninstilbene acid can be studied further in other in vitro and in vivo model to confirm the activities.

\section{ACKNOWLEDGEMENT}

Authors wish to thank Centre for Advance Research in Sciences (CARS), University of Dhaka, Dhaka-1000, Bangladesh for providing instrumental facilities to carry out the experiments.

\section{REFERENCES}

1. Yusoff, M., Hamid, H. and Houghton, P. 2014. Anticholinesterase inhibitory activity of quaternary alkaloids from Tinospora crispa. Molecules. 19, 1201-1211.

2. Darvesh, S., Hopkins, D.A. and Geula, C. 2003. Neurobiology of butyrylcholinesterase. Nat. Rev. Neurosci. 4, 131-138.

3. Greig, N.H., Utsuki, T., Ingram, D.K., Wang, Y., Pepeu, G., Scali, C., Yu, Q.S., Mamczarz, J., Holloway, H.W., Giordano, T. and Chen, D. 2005. Selective butyrylcholinesterase inhibition elevates brain acetylcholine, augments learning and lowers Alzheimer $\beta$-amyloid peptide in rodent. Proc. Natl. Acad. Sci.U.S.A. 102, 17213-17218.

4. Bullock, R. and Lane, R., 2007. Executive dyscontrol in dementia, with emphasis on subcortical pathology and the role of butyrylcholinesterase. Curr. Alzheimer. Res. 4, 277 293.

5. Jhee, S.S., Shiovitz, T., Hartman, R.D., Messina, J., Anand, R., Sramek, J. and Cutler, N.R. 2002. Centrally acting antiemetics mitigate nausea and vomiting in patients with Alzheimer's disease who receive rivastigmine. Clin. Neuropharmacol. 25, 122-123.

6. Kamal, M.A., Klein, P., Luo, W., Li, Y., Holloway, H.W., Tweedie, D. and Greig, N.H. 2008. Kinetics of human serum butyrylcholinesterase inhibition by a novel experimental Alzheimer therapeutic, dihydrobenzodioxepine cymserine. Neuro. Chem. Res. 33, 745-753. 
7. Mesulam, M.M., Guillozet, A., Shaw, P., Levey, A., Duysen, E.G. and Lockridge, O. 2002. Acetylcholinesterase knockouts establish central cholinergic pathways and can use butyrylcholinesterase to hydrolyze acetylcholine. Neurosci. 110, 627-639.

8. Basiri, A., Murugaiyah, V., Osman, H., Kumar, R.S., Kia, Y., Awang, K.B. and Ali, M.A. 2013. An expedient, ionic liquid mediated multi-component synthesis of novel piperidone grafted cholinesterase enzymes inhibitors and their molecular modeling study. Eur. J. Med. Chem. 67, 221-229.

9. Kitabchi, A.E., Umpierrez, G.E., Miles, J.M. and Fisher, J.N. 2009. Hyperglycemic crises in adult patients with diabetes. Diabetes care. 32, 1335-1343.

10. Zhao, T., Ding, K., Zhang, L., Cheng, X., Wang, CH. and Wang, ZT. 2013. Acetylcholinesterase and Butyrylcholinesterase inhibitory activities of $\beta$-Carboline and quinoline alkaloids derivatives from the plants of genus Peganum, J. Chem. 2013, Article ID 717232.

11. Ata, A., Iverson, C.D., Kalhari, K.S., Akhter, S., Betteridge, J., Meshkatalsadat, M.H., Orhan, I. and Sener, B. 2010. Triterpenoidal alkaloids from Buxus hyrcana and their enzyme inhibitory, anti-fungal and anti-leishmanial activities. Phytochem. 7, 1780-1786.

12. Ahmed, F., Ghalib, R.M., Sasikala, P. and Ahmed, K.M. 2013. Cholinesterase inhibitors from botanicals. Pharmacog. Rev. 7, 121.

13. Mahomoodally, F.M., Subratty, A.H., Gurib-Fakim, A. and Choudhary, M.I. 2012. Antioxidant, antiglycation and cytotoxicity evaluation of selected medicinal plants of the Mascarene Islands. BMC. Complement. Altern. Med. 12, 165.

14. Arif, T., Sharma, B., Gahlaut, A., Kumar, V. and Dabur, R. 2014. Anti-diabetic agents from medicinal plants: A review. Chem. Biol. Lett. 1, 1-13.

15. US, M.R., Mohd, K.S. and Zin, T. 2015. Some natural products and their secondary metabolites attributed towards diabetic cure: a review. Int. J. Pharm. Pharm. Sci. 7, 22-28.

16. Khan M.I.H. 2013. Isolation, identification and purification of endophytic fungi Cladosporium species and evaluation of its chemical and biological potentials. M. Pharm. Thesis. Department of Pharmaceutical Chemistry, University of Dhaka, Bangladesh.

17. Lukta, R. 2012. Chemical and biological investigation of $C$. linearis (Myrtaceare), M. Pharm. Thesis. Department of Pharmaceutical Chemistry, University of Dhaka, Bangladesh.

18. Shimu S. N. 2013. Chemical and biological investigation of Cajanus cajan (L.) Huth. M. Pharm Thesis. Department of Pharmacy, Stamford University Bangladesh.

19. Zinnurain R. 2013. Isolation of bioactive metabolites from the plant Carica papaya $L$. and one of its associated endophytic Fungi, M. Pharm. Thesis. Department of Pharmacy, Stamford University Bangladesh.
20. Ellman, G.L., Courtney, K.D., Andres Jr, V. and Featherstone, R.M. 1961. A new and rapid colorimetric determination of acetylcholinesterase activity. Biochemical Pharmacology. 7, 88-95.

21. Doctor, B.P., Toker, L., Roth, E. and Silman, I. 1987. Microtiter assay for acetylcholinesterase. Anal. Biochem. 166, 399-403.

22. Rieger, F., Shelanski, M.L. and Greene, L.A. 1980. The effects of nerve growth factor on acetylcholinesterase and its multiple forms in cultures of rat PC12 pheochromocytoma cells: increased total specific activity and appearance of the 16 S molecular form. Dev. Biol. 76, 238-243.

23. Nowotny, K., Jung, T., Höhn, A., Weber, D. and Grune, T. 2015. Advanced glycation end products and oxidative stress in type 2 diabetes mellitus. Biomol. 5, 194-222.

24. Reisberg, B., Doody, R., Stöffler, A., Schmitt, F., Ferris, S. and Möbius, H.J. 2003. Memantine in moderate-to-severe Alzheimer's disease. N. Engl. J. Med. 348, 1333-1341.

25. Shekhar C and Kumar S. 2015. Dual-cholinesterase inhibition by an aqueous extract of Emblica officinalis fruit and its mode of inhibition by kinetic study. Adv. Biomed. Pharma. 2, 7-12.

26. Rollinger, J.M., Schuster, D., Danzl, B., Schwaiger, S., Markt, P., Schmidtke, M., Gertsch, J., Raduner, S., Wolber, G., Langer, T. and Stuppner, H. 2009. In silico target fishing for rationalized ligand discovery exemplified on constituents of Ruta graveolens. Planta Med. 75, 195.

27. Onguéné, P.A., Ntie-Kang, F., Lifongo, L.L., Ndom, J.C., Sippl, W. and Mbaze, L.M.A. 2013. The potential of antimalarial compounds derived from African medicinal plants. Part I: a pharmacological evaluation of alkaloids and terpenoids. Malaria Journal. 12, 449.

28. Das, M.M. and Deka, D.C., 2017. Evaluation of anticancer and antimicrobial activity of arborinine from Glycosmis pentaphylla. J. Biol. Act. Prod. Nat. 7, 131-139.

29. Piboonprai, K., Khumkhrong, P., Khongkow, M., Yata, T., Ruangrungsi, N., Chansriniyom, C. and Iempridee, T. 2018. Anticancer activity of arborinine from Glycosmis parva leaf extract in human cervical cancer cells. Biochem. Biophys. Res. Commun. 500, 866-872.

30. Rachkova, M., Raikova, E. and Raikov, Z., 1991. New nitrosoureas and their spin-labeled derivatives influence dopa-oxidase activity of tyrosinase. Cancer. Biochem. Biophy. 12, 59-64.

31. Wszelaki, N., Kuciun, A. and Kiss, A. 2010. Screening of traditional European herbal medicines for acetylcholinesterase and butyrylcholinesterase inhibitory activity. Acta Pharmaceutica. 60, 119-128.

32. Abbas, G., Al-Harrasi, A., Hussain, H. and Hussain, J. 2015. Antiglycation therapy: Discovery of promising antiglycation agents for the management of diabetic complications, Pharm. Biol. 54, 198-206 
33. Fratiglioni, L., Winblad, B. and von Strauss E. 2007. Prevention of Alzheimer's disease and dementia. Major findings from the Kungsholmen project. Physiol. Behav, 92, 98-104.

34. Asaduzzaman, M., Uddin, M., Kader, M., Alam, A., Rahman, AA., Rashid, M., Kato, K., Tanaka, T., Takeda, M. and Sadik
G. 2014. In vitro acetylcholinesterase inhibitory activity and the antioxidant properties of Aegle marmelos leaf extract: implications for the treatment of Alzheimer's disease. Psychogeriatrics. 14, 1-10. 